\title{
TEKNOLOGI MEDIA PEMBELAJARAN PENGENALAN SEJARAH ISLAM DI INDONESIA BERBASIS ANDROID
}

\author{
Ali Akbar Ritonga ${ }^{1)}$, Masrizal $^{2)}$, Ibnu Rasyid Munthe ${ }^{3)}$ \\ Dosen Fakultas Sains dan Teknologi, Universitas Labuhanbatu \\ e-mail: aliakbarritonga@gmail.com \\ Dosen Fakultas Sains dan Teknologi, Universitas Labuhanbatu \\ e-mail: masrizal12045@gmail.com \\ Dosen Fakultas Sains dan Teknologi, Universitas Labuhanbatu \\ e-mail: ibnurasyidmunthe@gmail.com
}

\begin{abstract}
ABSTRAK
Teknologi Mobile merupakan sebuah teknologi yang banyak digunakan oleh masyarakat Indonesia sebagai alat komunikasi untuk saling terhubung, baik dibidang Bisnis dan juga sebagai media pembelajaran.Teknologi mobile berbeda dengan personal computer atau perangkat komputer perbedaan yang mencolok ada pada ukuran dan kemampuan dalam mendapatkan informasi. Dalam proses belajar mengajar baik sekolahsekolah dan diperguruan tinggi berbasis pendidikan islam seperti pesantren,MAN, MTS, Kampus IAIN dan juga sekolah umum membutuhkan teknologi mobile yang memuat isi sejarah-sejarah islam di Indonesia. Melalui aplikasi ini pembejalaran sejarah islam mulai dari sabang hingga merauke mulai darimasuknya sampai penyebaran islam diindonesia akan lebih memudahkan para guru, santri siswa bahkan mahasiswa mengenal perjalanan islam itu sendiri. Dengan memanfaatkan teknologi, audio, animasi, video, dan text digabung dalam sebuah aplikasi yang semua pengguna smartphone dapat melihat dan belajar tentang sejarah islam di Indonesia.
\end{abstract}

\section{Kata kunci: sejarah, Android, Teknologi Mobile}

\section{ABSTRACT}

Mobile technology is a technology that is widely used by Indonesians as a means of communication to connect to one another, both in the business sector and also as a learning medium. Mobile technology is different from personal computers or computer devices. The striking difference is in the size and ability to obtain information. In the teaching and learning process, both schools and higher education institutions based on Islamic education such as pesantren, MAN, MTS, IAIN Campus and also public schools need mobile technology that contains the contents of Islamic histories in Indonesia. Through this application, learning about the history of Islam from Sabang to Merauke, starting from the entry to the spread of Islam in Indonesia, will make it easier for teachers, students, students and even students to know the journey of Islam itself. By utilizing technology, audio, animation, video, and text are combined in an application that all smartphone users can see and learn about the history of Islam in Indonesia.

Keywords: history, Android, Mobile Technology. 


\section{PENDAHULUAN}

Teknologi Mobile adalah salah satu teknologi yang digunakan oleh masyarakat Indonesia sebagai alat komunikasi, Bisnis dan juga sebagai media pembelajaran.Teknologi mobile berbeda dengan personal komputer perbedaan yang mencolok salah satunya ada pada ukuran layar dan kemampuan komputasinya. Karena itu diperlukan suatu adaptasi dari server yang memberikan isi layanan mobile learning, agar sesuai dengan kapasitas komputasi device pada client.Dalam proses pembelajaran di sekolah-sekolah dan Perguruan tinggi yang berbasis pendidikan islam seperti MAN, Pesantren, kampus IAIN dan juga sekolah umum, dibutuhkan media mobile yang memudahkan dalam pembelajaran pendidikan islam. Sejarah perkembangan islam di Indonesia yang ada di Buku-Buku sejarah masih bersifat parsial dan Minimnya pemberitahuan secara kolektif baik di pendidikan dan di Masyarakat , Sejatinya sejarah islam adalah sejarah yang tidak boleh diubahubah oleh pihak siapapun karena sejarah islam adalah bukti bahwa islam pernah menorehkan tinta sejarah peradaban di dunia dan khususnya di Indonesia dari sabang hingga meroke.Di Indonesia ilmu sejarah, Baik sejarah nasional maupun sejarah kebudayaan Islam (SKI) telahmenjadi salah satu mata pelajaran wajibdalam kurikulum, sejak sekolah dasar.Yang menjadi pertanyaan kemudian adalahsudahkah pembelajaran sejarah berjalandengan baik?Pada kenyataannya, pengajarantransfer ilmu guru ke murid di dalam kelasmelalui komunikasi satu arah. Murid hanyamenjadi obyek pasif yang mempunyaikewajiban menghafal catatan yangdiberikan guru supaya bisa menjawab soal-soal yang akan diujikan. Metodepengajaran sejarah semacam ini telah menjadikan pelajaran sejarahmembosankan. Kemudian tak memberikansentuhan emosional karena siswa merasatak terlibat aktif di dalam prosespembelajarannya.Metode

pembelajaran yang kakuberakibat buruk untuk jangka waktupanjang dan berpotensi memunculkangenerasi yang mengalami lupa sejarahbangsa sendiri.

Aplikasi ini berisi materi tentang sejarah dan biografi tokoh yang disajikan dengan memanfaatkankonten-konten multimediaberupa : Animasi, Audio, dan Text, Sehingga menarik dan tidak membosankan. Untuk mendukung aplikasi ini juga disertakan kuisinteraktif berupa soal pilihan ganda, guna menambah daya ingat dan kemampuan pembaca dalam mendalami materi yang didapat dari aplikasi ini.

Berdasarkan permasalahan di atas, maka penulis tertarik untuk melakukan penelitian tentang teknologi media pembelajaran sejarah Islam di Indonesia Berbasis Android.

\section{Landasan Teori \\ 2.1 Definisi Sejarah}


sejarah merupakan catatan seluruh pengalaman, baik secara individu maupun kolektif bangsa/nation dimasa lalu tentang kehidupan umat manusia. Sedangkan menurut J. Banks, Semua peristiwa masa lalu adalah sejarah (sejarah sebagai aktualitas).Sejarah dapat membantu siswa untuk memahami perilaku manusia dalam tujuan masa kini dan masa depan yang baru. Dari kedua definisi tersebut maka dapat disimpulkan bahwa kejadian di masa lampau mengenai seorang tokoh atau jatuh bangunnya sebuah peradaban dapat membantu siswa dalam memahami kehidupan manusia di masa lampau dan dapat memprediksi kehidupan manusia di masa yang akan datang. Sejarah dapat digolongkan sebagai ilmu apabila ia memiliki syarat-syarat dari suatu ilmu pengetahuan atau syarat-syarat ilmiah. Syarat-syarat keilmuan yang dimaksud adalah:
a. Ada objek masalahnya
b. Memiliki metode
c. Tersusun secara sistematis
d. Menggunakan pemikiran yang rasional
e. Memiliki kebenaran yang objektif

\subsection{Pengertian Media}

Media berasal dari bahasa latin merupakan bentuk jamak dari "medium" yang secara harfiah berarti "perantara" atau "pengantar".Menurut Criticos media merupakan salah satu komponen komunikasi, yaitu sebagai pembawa pesan dari komunikator menuju komunikan. Berdasarkan beberapa pendapat tersebut dapat disimpulkan bahwa media adalah segala sesuatu benda atau komponen yang dapat digunakan untuk menyalurkan pesan dari pengirim ke penerima sehingga dapat merangsang pikiran, perasaan, perhatian dan minat dalam proses belajar.

\subsection{Pengertian Media Pembelajaran}

Pada mulanya, media pembelajaran hanya merupakan alat bantuvisual yang digunakan oleh guru untuk mengajar. Sekitar pertengahan abad Ke -20 usaha pemanfaatan visual dilengkapi dengan menggunakan alat audio, sehingga lahirlah alat bantuaudio-visual. Sejalan dengan perkembangan ilmu pengetahuan dan teknologi (IPTEK), khususnya dalam bidang pendidikan, saat ini penggunaan alat bantu atau media pembelajaran menjadi semakin luas dan interaktif, seperti adanya komputer, internet dan handphone. Media pembelajaran dibagi menjadi beberapa media yaitu:

1. Media visual : Grafik, diagram, chart, bagan, poster, kartun, komik.

2. Media audio : Radio, tape recorder, laboratorium bahasa, dan sejenisnya.

3. Projected still media : Slide, over head projektor (OHP), in focus dan sejenisnya

Projected mation media : fim, televisi, video (VCD, DVD, VTR), komputer dan sejenisnya. Pada dasarnya, bukan media pembelajaran yang menentukan hasil belajar, tetapi keberhasilan menggunakan media pembelajaran dalam proses pembelajaran untuk meningkatkan hasil belajar tergantung pada isi pesan, cara 
menjelaskan pesan dan karakteristik penerima pesan.

\subsection{Android}

Menurut Nazruddin Safaat H. (2012) "Android adalah sebuah sistem operasi untuk perangkat mobil berbasis linux yang mencakup sistem informasi, middleware dan aplikasi'.Android dikembangkan bersama antara Google, HTC, Intel, Motorola, Qualcomm, TMobile, NVIDIA yang tergabung dalam OHA (Open HandsetAlliance) dengan tujuan membuat sebuah standar terbuka untuk perangkat bergerak (mobile device). Android menyediakan platform terbuka bagi para pengembang untuk menciptakan aplikasi mereka

\subsection{Arsitektur Android}

Secara garis besar, arsitektur android dapat dilihat pada Gambar 2.5, dimana android itu terdiri dari beberapa layer, diantaranya :application, application framework, libraries, android run time, dan linux kernel.

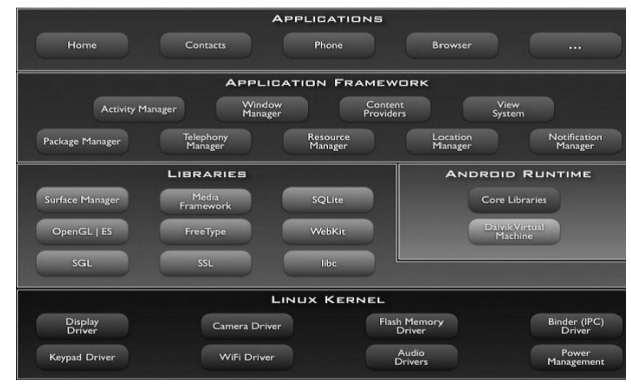

a. Application dan Widgets

Application and widgets ini adalah layersebagai pengubung dengan aplikasi, di mana biasanya aplikasi tersebut dapat didownload, diinstalasi dan kemudian dijalankan. Di layer terdapat aplikasi inti termasuk klien email, program SMS, kalender, peta, browser, kontak, dan lainlain. Semua aplikasi ditulis menggunakan bahasa pemrograman Java.

\section{b. Application Frameworks}

layerdimana para pembuat aplikasi melakukan pengembangan/ pembuatan aplikasi yang akan dijalankan di system operasi Android, karena pada layer inilah aplikasi dapat dirancang dan dibuat, seperti content-providers yang berupa SMS dan panggilan telepon.Komponenkomponen yang termasuk ke dalam Application Framework adalah sebagai berikut :Views, Resource Manager Notification, Manager, Activity Manager

\section{c. Libraries}

Libraries adalah layer dimana fitur-fitur android berada biasanya para pembuat aplikasi kebanyakan mengakses libraries untuk menjalankan aplikasinya. Berjalan diatas kernel, layer ini meliputi berbagai library $\mathrm{C} / \mathrm{C}++$ inti seperti Libc dan SSL

\section{METODE PENELITIAN}

Pada penelitian ini membahas tentang perancangan perangkat lunak media pembelajaran dengan menggunakan bahasa Java berbasis Pemograman Android, Mata pelajaran Sejarah Islam yang ada di MAN II kota Padang. Sistem yang dirancang berbasiskan android 
dimana data-data pendukung penelitian ini berasal dari data-data wawancara dan buku pelajaran sejarah serta teknik pengumpulan data merupakan cara yang dilakukan dalam peroses pengumpulan data

\subsection{Metode Pengumpulan Data}

Ada beberapa teknik pengumpulan data yang digunakan untuk mendapatkan data dan informasi yang tepat dan akurat, maka pada penelitian ini pengumpulan data dilakukan dengan beberapa metode, antara lain :

a. Studi Pustaka

Penelitian ini dilakukan dengan mempelajari beberapa buku literatur yang berhubungan dengan penulisan tugas akhir ini dan beberapa referensi lainnya.

b. Wawancara

Pengumpulan data dengan cara mengadakan Tanya jawab langsung kepada pihak yang terkait, yang dapat memberikan penjelasan langsung ataupun data sebagai pelengkap penulisan tugas akhir ini

c. Observasi

Melalui Jaringan Internet untuk mendapatkan gambaran aplikasi dan informasi lainnya yang mendukung penelitian.

\subsection{Analisis Kebutuhan Sistem}

Kebutuhan sistem aplikasi mobile learning sejarah islam di Indonesia yang dirancang ditentukan berdasarkan kebutuhan yaitu, sebagai berikut :
1. Kebutuhan sistem perangkat mobile atau smartphone yang banyak digunakan oleh calon pengguna, khususnya bagi pelajar yang mempelajari ilmu sejarah islam.

2. Kebutuhan dan cakupan materi yang akan disediakan dalam program aplikasi

Memudahkan pengguna (users), Guru dan Pelajar dalam efisiensi dalam mempelajari sejarah islam di Indonesia.

\subsection{UML (Unified Modeling Language)}

UML merupakan singkatan dari UnifiedModeling Language yang berarti bahasa pemodelan standar[1]UML adalah sebuah bahasa yang berdasarkan grafik/gambar untuk memvisualisasi, menspesifikasikan, membangun, dan pendokumentasian dari sebuah sistem pengembangan software berbasis OO(Object-Oriented). UML tidak hanya merupakan sebuah bahasa pemograman visual saja, namun juga dapat secara langsung dihubungkan ke berbagai bahasa pemograman, seperti JAVA, C++, Visual Basic, atau bahkan dihubungkan secara langsung ke dalam sebuah object-oriented database. Adapun jenis jenis diagram diagram yang ada pada uml sebagai berikut :Use Case Diagram, Activity Diagram Sequence Diagram, Communication Diagram (Collaboration diagram in versi 1.x), Class Diagram, State Machine Diagram (Statechart diagram in versi 1.x), Component Diagram, Deployment Diagram, Composite Structure Diagram, Interaction 
Overview Diagram, Object

DiagramPackage Diagram, Timing

Diagram.

\subsection{Use Case Diagram}

Adapun use case Diagram Media pembelajaran sejarah berbasis android adalah sebagai berikut :

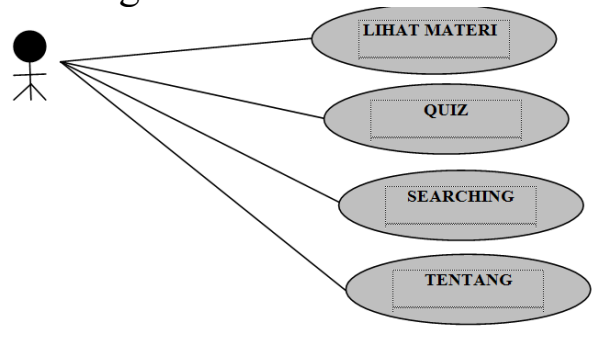

Gambar. 3.1 Use Case Diagram

Penjelasan Gambar 3.1 Use case bekerja dengan cara mendeskripsikan tipe interaksi antara user sebuah sistem dengan sistemnya sendiri melalui sebuah cerita bagaimana sebuah sistem dipakai. Use case merupakan konstruksi untuk mendeskripsikan bagaimana sistem akan terlihat di mata user. Sedangkan use case diagram memfasilitasi komunikasi diantara analis dan pengguna serta antara analis dan client.[2]

\subsection{Activity Diagram Materi}

Berikut merupakan Activity Diagram untuk melihat Materi

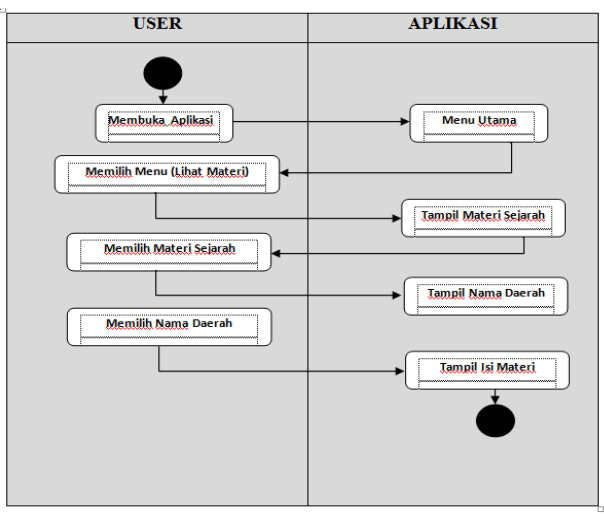

\section{Gambar 3.2 Activity Diagram Materi}

Activity diagrams menggambarkan berbagai alir aktivitas dalam sistem yang sedang dirancang,[3] bagaimana masingmasing alir berawal, decision yang mungkin terjadi, dan bagaimana aplikasi berakhir.

\subsection{Sequence Diagram}

Berikut merupakan Sequence Diagram Utama.

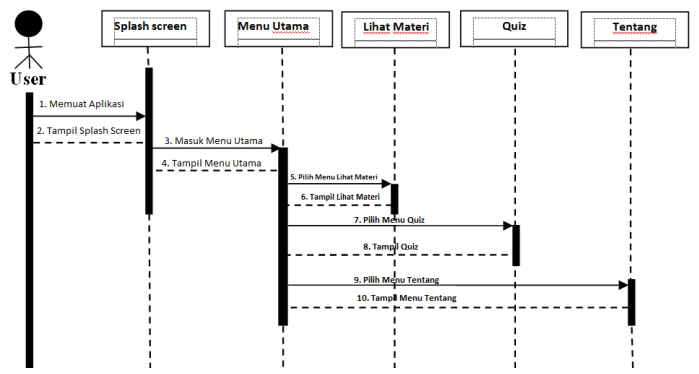

Gambar 3.3 Sequence Diagram Utama

\subsection{Rancangan Antar Muka Sistem (Interface)}

Rancangan tampilan program aplikasi yang akan dibangun terdiri dari beberapa content yang dirancang seinteraktif mungkin sehingga memungkinkan pengguna dapat mengoperasikan aplikasi secara optimal.

\subsubsection{Rancangan Tampilan Menu Utama}

Pada tampilan menu utama terdapat Beberapa Kategori : Materi,Quiz, Keluar dan tentang dan juga dilengkapi dengan pilihan pada masing-masing Kategori. 


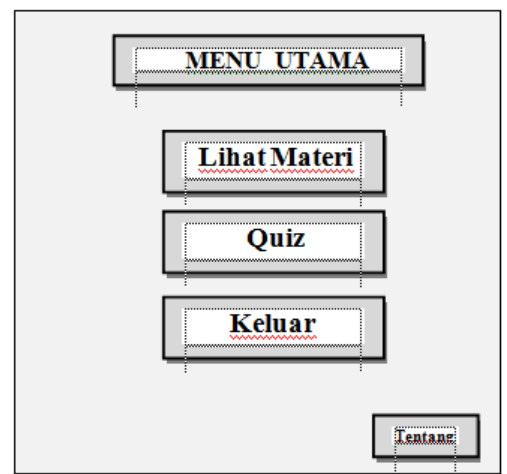

Gambar. 3.4 Rancangan Menu utama

Penjelasan :

Pada gambar 3.4 tampilan Menu Aplikasi akanmenjelaskan beberapa tombol yaitu:
a. Tombol "Menu": pelajaran yang akan diajarkan.
b. Tombol "Quiz": latihan pelajaran.
c. Tombol "Keluar": keluar dari aplikasi.
d. Tombol "Tentang": Info Aplikasi dan Biodata

\subsubsection{Rancangan Tampilan Lihat Materi}

Halaman lihat materi merupakan isi dari aplikasi media pembelajaran ini , dimana di dalam halaman lihat materi terdapat 5 Pilihan Kategori materi , Kategori materi ini adalah Nama - Nama Pulau yang terbesar Di Indonesia: Sumatera, Jawa, Kalimantan, Sulawesi dan Papua

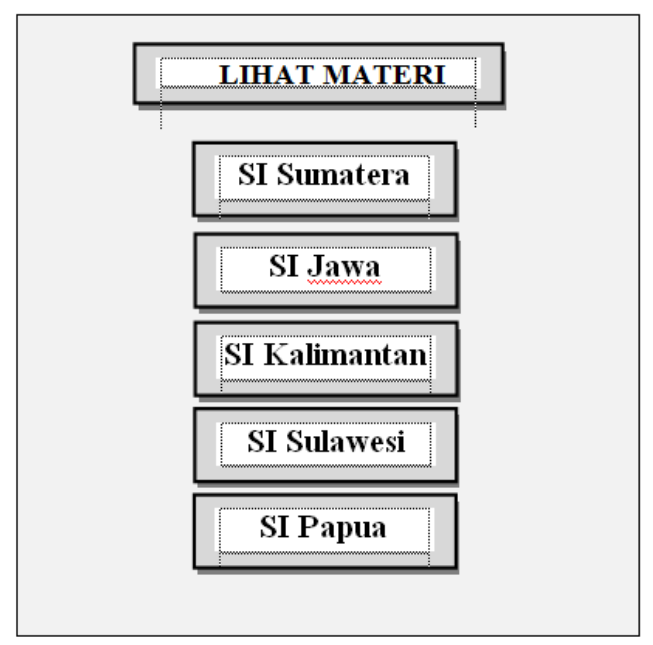

Gambar 3.5 Tampilan Lihat Materi

\subsubsection{Rancangan Halaman Quiz}

Perancangan tampilan quiz seperti gambar 3.6 akan ditampilkan dalam bentuk nomor soal, Pilihan jawaban, dan hasil jawaban.

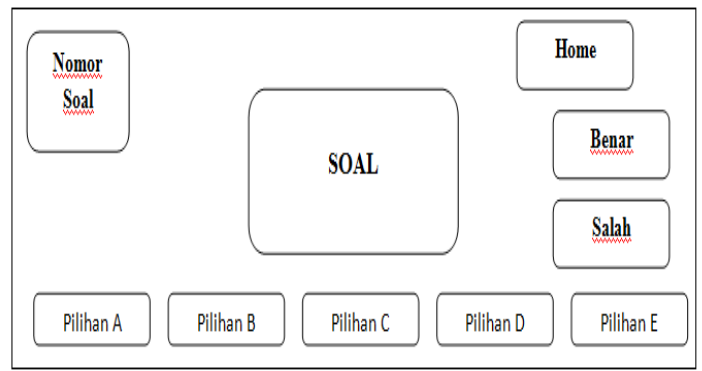

Gambar 3.6 Tampilan Quiz

Penjelasan :

Pada gambar 3.6 menjelaskan sebuah tampilan quiz yang akan dibuat pada aplikasi media pembelajaran yang bertujuan untuk melatih pengguna.

\section{HASIL DAN PEMBAHASAN}

4.1 Hasil dan Pembahasan

Aplikasi media pembelajaran Sejarah islam ini dirancang agar dapat menjadi salah satu pendukung dalam proses belajar 
-mengajar bagi siswa dan siswi disekolah khusunya sekolah islam di indonesia. aplikasi ini berbasis offline dan memanfaatkan beberapa Multimedia sehingga pengguna bisa menggunakan dengan mudah dan santai.

Didalam aplikasi terdapat kategori materi yang terdiri dari Sejarah Islam di Masing-Masing Pulau Di Indonesia Serta pada aplikasi tersedia Quiz yang diimplementasikan berupa PertanyaanPertanyaan dengan skor nilai yang telah ditentukan. Penggunaan mobile device banyak memberikan kemudahan kepada penggunanya, karena lebih fleksibel untuk dapat dibawa kemana saja, sehingga aplikasi mobile Pegenalan Sejarah Islam dapat diakses oleh pengguna setiap waktu melalui mobile device dengan system operasi android.

\subsubsection{Tampilan Halaman Utama}

Halaman awal merupakan tampilan awal masuk aplikasi. Halaman awal berupa splash yang menunjukan latar belakang yang menggunakan image di sertai dengan judul aplikasi. Rancangan tampilan halaman splash awal dapat dilihat pada gambar dibawah ini:

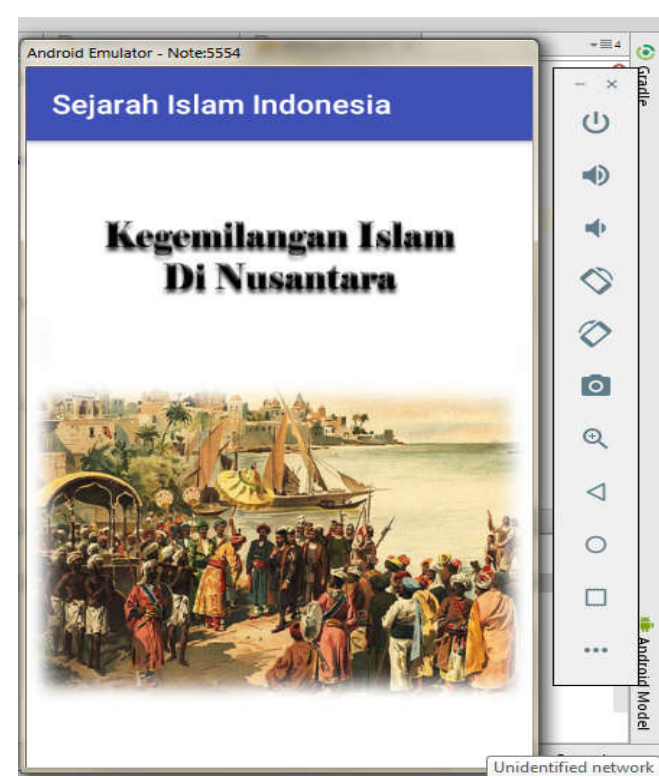

Gambar 4.1SplashAwal

\subsubsection{Antarmuka Halaman Menu Utama}

Pengguna akan masuk kehalaman materi saat memilih Tombol Lihat Materi , di Halaman lihat materi sejarah-sejarah perkembangan islam, kesultananan islam serta Nama-nama sultan.

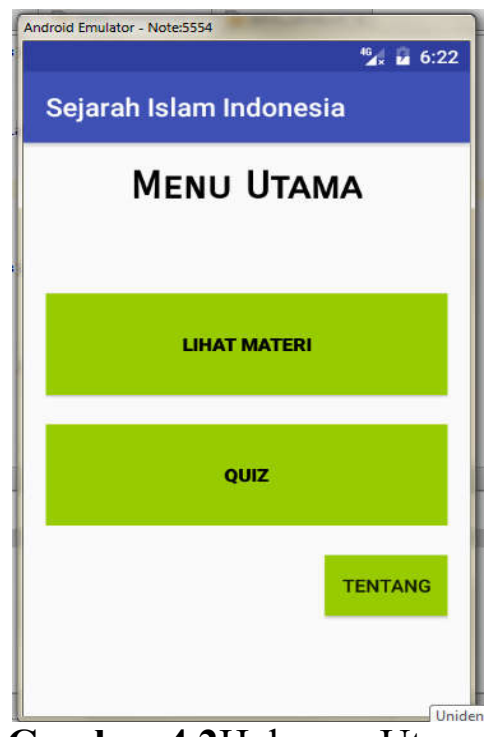

Gambar 4.2Halaman Utama

\subsubsection{Antarmuka Halaman Menu Materi}

Jika kita memilih salah satu materi maka akan muncul Sejarah-sejarah islam 
di Nusantara. Di dalam halaman lihat materi terdapat tombol stop backsoud.

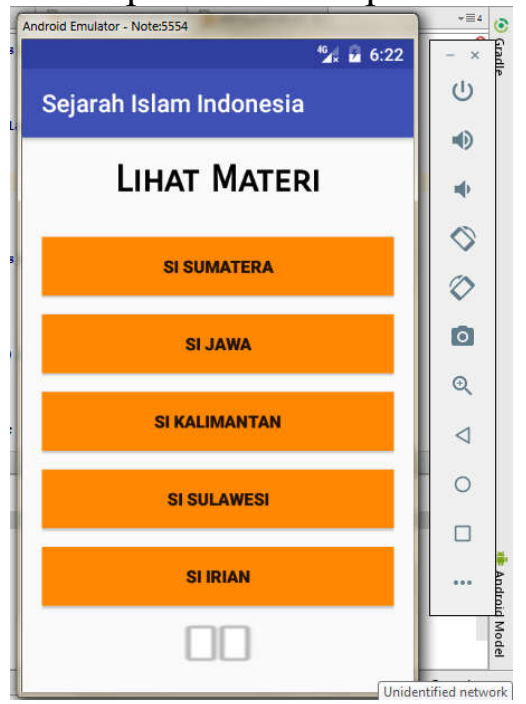

Gambar 4.3Halaman Menu Materi

\subsubsection{Antarmuka Halaman IsiMateri}

Pengguna akan masuk kehalaman isi materi saat memilih kategori pulau, ada beberapa sub materi nama-nama kesultanan Diantaranya : Samudra Pasai, Demak, Gowa Tallo, Bima dan lain-lain. Ketika kita pilih salah satu akan muncul detail materi berisi gambar serta penjelasannya. Berikut beberapa gambar isi materi

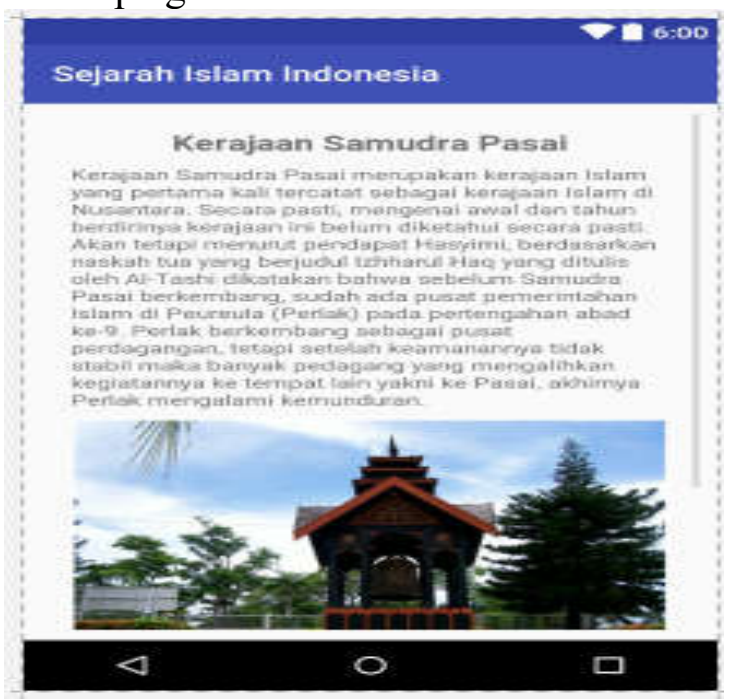

Gambar 4.4 Halaman Isi Materi
5 KESIMPULAN DAN SARAN

5.1 Kesimpulan

Berdasarkan pembahasan yang dilakukan dalam penelitian maka dapat diambil kesimpulan bahwa dengan adanya aplikasi Pengenalan Sejarah Islam Di Indonesia akan mempermudah Guru, pelajar atau masyarakat umum untuk mengenal sejarah islam di Indonesia. Aplikasi ini dipaketkan menjadi sebuah file APK yang merupakan paket aplikasi agar bisa diinstall ke perangkat smartphone atau tablet android. Aplikasi ini berjalan pada smartphone android dengan versi minimal 4.0-4.0.2 (ice Cream Sandwich) dengan API minimal versi 15 dan competible dengan versi android terbaru

\subsection{Saran}

Setelah selesainya perancangan Aplikasi Pengenalan Sejarah Islam di Indonesia ini masih terdapat beberapa kelemahan yaitu pada materi aplikasi ini yang belum sepenuhnya lengkap dan Fasilitas Multimedia yang belum terlengkapi Baik Video, Musik, Animasi dll dan juga belum menggunakan Database sehingga kurang efektif. Diharapkan aplikasi ini dapat membantu Siswa atau masyarakat umum yang mempelajari Sejarah Kisah Islam (SKI) dengan menggunakan aplikasi ini sebagai media pembelajaran alternative . 


\section{DAFTAR PUSTAKA}

[1] J. I. Sinaga, M. Mesran, and E. Buulo, "Aplikasi Mobile Pencarian Kata Pada Arti Ayat Al-Qur' an Berbasis Android Menggunakan ...," J. INFOTEK, vol. II, no. Juni 2016, pp. 68-72, 2016.

[2] I. F. M. Rachmat, ."Melalui aplikasi tersebut diharapkan bisa membantu permasalahan akibat kurangnya pengetahuan dalam pembagian harta warisan. Perancangan aplikasi ini menggunakan metode berorientasi objek yaitu," vol. 5, no. 2, 2017.

[3] N. M. Astiti, "Analisa dan perancangan aplikasi pembelajaran matematika berbasis android," Konf. Nas. Sist. dan Inform. 2015, vol. 9, no. 10, pp. 982-991, 2015.

[4] R. Novita and S. Z. Harahap, "PENGEMBANGAN MEDIA PEMBELAJARAN INTERAKTIF PADA MATA PELAJARAN SISTEM KOMPUTER DI SMK," JURNAL INFORMATIKA, vol. 8, no. 1, pp. 36-44, Jan. 2020.

[5] A. Nastuti and S. Z. Harahap, "TEKNIK DATA MINING UNTUK PENENTUAN PAKET HEMAT SEMBAKO DAN KEBUTUHAN HARIAN DENGAN MENGGUNAKAN ALGORITMA FP-GROWTH (STUDI KASUS DI ULFAMART LUBUK ALUNG)," JURNAL INFORMATIKA, vol. 7, no. 3, pp. 111-119, Sep. 2019.

[6] Samsir and S. Z. Harahap,
"APPLICATION DESIGN RESUME MEDICAL BY USING MICROSOFT VISUAL BASIC. NET 2010 AT THE HEALTH CENTER APPOINTMENTS," International Journal Of Science, Technology \& Management, vol. 1, no. 1, pp. 14-20, Jun. 2020.

[7] S. Z. Harahap and Samsir, "APPLICATION DESIGN THE DATA COLLECTION FEATURES OF THE HOTEL SHADES OF RANTAUPRAPAT USING VBNET," International Journal Of Science, Technology \& Management, vol. 1, no. 1, pp. 1-6, Jun. 2020.

[8] M. Nasution, S. Pohan, and S. Z. Harahap, "Implementasi Obrim (Option-Based Risk Management) Sebagai Framework Investasi Teknologi Informasi Perguruan Tinggi (Studi Kasus: Amik Labuhan Batu)," JURNAL INFORMATIKA, vol. 8, no. 1, pp. 26-35, Jan. 2020.

[9] S. Z. Harahap and M. H. Dar, "APLIKASI DAN PERANCANGAN SISTEM INFORMASI PEMESANAN PADA UPI CONVENTION CENTER DENGAN MENGGUNAKAN BAHASA PEMROGRAMAN PHP DAN MYSQL," JURNAL INFORMATIKA, vol. 6, no. 3, pp. 24-27, Sep. 2019.

[10] M. H. Dar and S. Z. Harahap, "IMPLEMENTASI SNORT INTRUSION DETECTION 
SYSTEM (IDS) PADA SISTEM JARINGAN KOMPUTER," JURNAL INFORMATIKA, vol. 6, no. 3, pp. 14-23, Sep. 2017.

[11] S. Samsir, D. Indra, G. Hts, and S. Z. Harahap, "SPK Untuk Pemilihan Kepala Sekolah Menggunakan Metode Saw dan Profile Matching," U-NET J. Tek. Inform., vol. 4, no. 1, pp. 7-12, 2020.

[12] P. Iwan, S. Z. Harahap, and A. A. Ritonga, "RANCANG BANGUN TEMPAT SAMPAH OTOMATIS PADA UNIVERSITAS LABUHANBATU," INFORMATIKA, vol. 8 , no. 2, pp. $1-5,2020$.

[13] M. Siddik and S. Z. Harahap, "UNET: Jurnal Teknik Informatika LPPM - Universitas Al Washliyah Labuhanbatu $12 \mid \mathrm{P}$ a g e U-NET: Jurnal Teknik Informatika LPPM Universitas Al Washliyah Labuhanbatu 13 | P a g e," U-NET J. Tek. Inform., vol. 3, no. 3, pp. 12-17, 2019. 